\title{
Trainee teachers' experiences using contextual teaching and learning: Implications for incorporation of indigenous knowledge in instructional design
}

\author{
Muzwangowenyu Mukwambo ${ }^{1 *}$ \\ ${ }^{1}$ University of Namibia, $N A M I B L A$
}

\begin{abstract}
Some schools do not have local formal work environments enabling learners to interact with members in community of practice. This is noticeable in schools in developing countries, including the north eastern Zambezi Region of Namibia, where the study took place. To close the gap in which trainee science and mathematics teachers who were the participants failed to contextualize teaching and learning (CTL) using formal work situations, this qualitative study investigated use of Indigenous Knowledge (IK) practices as an alternative. A cultural group presented IK practices which trainees observed and participated. Pottery making, an IK practice, reflects Science knowledge which teachers sometimes shun. Audio-visual, lesson plans and interviews were also used to generate data. To intervene Cultural historical activity theory (CHAT) was used as a tool. Revelations are trainee teachers in rural schools initially viewed CTL designing as impossible. Further, trainees engaged with CTL through allowing IK to compliment modern science and were equipped with pedagogical tools.
\end{abstract}

\begin{abstract}
Keywords
practices,

indigenous knowledge,

CTL

Received: 18 Jan 2016

Revised: 10 Feb 2016

Accepted: 1 Mar 2016
\end{abstract}

DOI: $10.20897 /$ lectito.201611

\section{INTRODUCTION AND CONTEXT}

The (Namibian National Curriculum for Basic Education [NNCBE] 2010) recommends learner-centered approach as an appropriate pedagogy to use in teaching and learning. It further encourages the use of all knowledge sources to promote learner-centered teaching and learning. In learner-centered pedagogy learners are engaged in classroom talk. Sometimes classroom talk is not achieved as learners lack the language and formal work environments where they can be apprenticed to interact and acquire science language with members in practice (Lave \& Wenger, 1991). Bond (2004) refers to this as cognitive apprenticeship and considers it to be analogous to ways artisans acquire academic knowledge and/or skills. Members in a community of practice are those who are engaged in work environments where concepts taught are applied or used. These members in a community offer informal learning where learners are able to learn from their experience.

The absence of formal work environments in an area where a school is situated comes as a challenge to teachers attempting to exploit CTL. The expectation is that trainees design contextualized teaching and learning activities in which learners interact with members in community of practice. However, schools in

\footnotetext{
${ }^{*}$ Correspondence to: m.mukwambo@gmail.com
}

Pedagogical Research, 2016. (C) Muzwangowenyu Mukwambo. This is an Open Access article distributed under the terms of the Creative Commons Attribution 4.0 International License (http://creativecommons.org/licenses/by/4.0/), allowing third parties to copy and redistribute the material in any medium or format and to remix, transform, and build upon the material for any purpose, even commercially, provided the original work is properly cited and states its license. 
rural areas often do not have formal work environments near their surroundings. This can also be the case in urban and peri-urban centres, if the economy does not support major industries or enterprises. In such schools, theories, laws or concepts in Science and Mathematics cannot be taught using CTL instructional design thus rendering them an inert character.

For Science and Mathematics concepts not to be inert, it is imperative that trainee teachers learn to engage in CTL as an antidote to knowledge transmission (Whitehead 1929; Freire 1993). Absence of formal work environments and recognized communities of members in practice near certain schools paved the way for this study. The study proposes to infuse IK in instructional design to facilitate trainees to engage with CTL. With this view, the study sought to answer the following research questions: (a). What are the experiences of trainees in infusing IK in order to engage CTL instructional design during practices? (b). How do teacher trainees perceive that CTL instructional design, using IK practices, can be implemented in schools?'

\section{CONCEPTUAL FRAMEWORK}

\section{Contextualized teaching and learning}

(Berns \& Erickson, 2001) suggests that CTL is a teaching and learning practice in which teachers "relate subject matter content to real world situations" (p. 2). A broadened definition of CTL is from Mazzeo (2008) who define CTL as pedagogical styles that:

'Seamlessly link the learning of foundational skills and academic or occupational content by focusing teaching and learning squarely on concrete applications in a specific context that is of interest to the student' (p. 4).

For instance, clay is one of the materials that science learners examine at school. A community member involved in pottery is an expert as she/he processes clay to produce a durable form. The potter grinds the clay to produce smaller grains. Smaller grains speed up the reaction between clay and water. After working on it, he/she moulds cultural artefacts. Some of the moulded cultural artefacts are geometrical shapes, which Mathematics learners learn. When clay artefacts are wet, different patterns are drawn of which some are geometrical shapes. The knowledge of patterns is the basis of knowing mathematics. The clay artefact is heathardened. Gerdes (2001) in his analysis of geometrical shapes in houses build in Mozambique recommends that bringing such ideas makes learning and teaching of Mathematics easy. Gerdes (2001) further points out that mathematical teaching and methods used are different in different cultures but teachers must select and analyse appropriate activities and incorporate them to develop students' potentials.

The conclusion is that the activities of a potter reflect a lot of Science and Mathematics. Teachers of these subjects rarely discuss or take learners to pottery sites in order to relate theoretical knowledge with applied and experienced knowledge; and, potters are not invited to work as collaborators, to scaffold Science and Mathematics discourses.

Contextualized teaching and learning pedagogical practices (CTLPP) brings authentic context that helps aid learners see the relevance of science and maths concepts the teacher presents. This creates a pathway for learners to understand the concept or phenomena the teacher discusses. Other features of CTLPP are teachers assume a collaborative role, learners do reflections, coaching becomes possible, multiple practices, and articulation and all can be achieved using IK. Furthermore, it is compatible with the motivation theory and the idea that students need to be self-regulated in order to learn.

In motivation theory learners learn if they are 1) self-directed, 2) enriched by a diversity of personal experience and culture is brought into the classroom, 3) ready to learn, 4) life-centered tasks are considered in the teacher's discourses, task centered and problem-centered and 5) motivated by internal factors. Mezirow (2000) understand this as learners make links with new knowledge the teachers present.

(Brown, Collins and Duguid, 1989) argue as they support situated cognition that, deep learning takes place when social and physical contexts are addressed. This presents a similar situation in CTL. However, sometimes teachers still fail to say how we can address the social and physical context in an African context where formal work environments are sometimes quite distant from certain schools.

Schools in developing sub-Saharan African countries sometimes lack the factories and institutions where subject knowledge is applied, where learners can be apprenticed. Gadgets for information and communication technology (ICT) that can be used for simulation and to bring dynadiagrams are unevenly distributed or absent in certain schools. Yet, Lave and Wenger (1991) suggest that apprentices need to participate in the culture of practice. In the absence of formal work environments, it might seem practically impossible to provide the necessary ingredients: (a) authentic context, (b) authentic activity, (c) access to an 
expert, (d) multiple roles and perspectives, (e) collaborative construction of knowledge, (f) coaching and scaffolding, (g) reflections to enable abstractions to be formed, (h) articulation to enable tacit knowledge to be formed, and (i) assessment of learning.

However, even though rural schools in sub-Saharan African countries may seem short-changed on implementation of CTLPP on account of limited formal infrastructure, teachers in Mathematics and Science can still adapt CTL to suit the culture of the school. IK use as an alternative to formal work environment is sanctioned and implemented, cultural artefacts, cultural practices and local languages reflecting Science and Mathematics knowledge can be used to place learners nearer to those in the community of practice as attested in the discussion below.

An example in the Zambezi Region of Namibia reveals that people swim in the Zambezi River, which is infested with crocodiles. The point where they swim is selected on the basis that it is rocky. Crocodiles, whose bellies are very soft, find the place inaccessible and inhabitable. An attempt to reach the rocky area by a crocodile inflicts wounds on its belly. Another example is crossing the Zambezi River at points where the river is wide. At these points, the velocity of flowing water is less than at a point where water flow is constricted. At constricted points of the river, the velocity is high. Crossing at constricted points of the river using dugout canoes or swimming exposes people to the risk of being carried further down the river or have the former capsize. That is, their IK of fluid flow is what Bernoulli's theorem in Physical science explains:

If such situations, which speak a lot of science, are recognized as learning opportunities and learners in Science are taken to these points or teachers refer to them during discourses, they can provide authentic context, authentic activity and bring the learners nearer to the experts as advocated in CTL.

In Mathematics, as teachers address numeracy, words such as 'less than', 'heavier than', are introduced. This endeavour builds skills in learners so that they can order, compare and detect patterns in numbers and measures. However, sometimes this is done theoretically and not easily understood by learners. Yet in learners' communities, for example, the production of cooking oil prepared from seeds from natural fruits like mungongo illustrates that oil is lighter than water and forms a top layer while water, which is heavier than oil, settles as a lower layer. This would also provide a good lesson in density. If learners are brought to these situations, learning the language of Mathematics and Science will be facilitated. Equipped with their cultural practices, Mathematics and Science jargon, community members can be used as teaching and learning collaborators. Their collaboration motivates learners to behave like mathematicians and scientists. Such activities may place learners in the pipeline to be scientists and mathematician.

Encounters with community members as they collaborate to make CTL a success serve versatile roles. A visit to a potter discussed above will not only serve to learn about materials in a contextualized environment. Knowledge of evaporation, sublimation, semi-permeability of cured clay can be discussed. The community's indigenous ways of knowing nature can then be used to contextualize teaching and learning as pedagogical content knowledge (PCK) and pedagogical technical content knowledge (Shullman, 1987). The IK examples given above serve to attest how CTL can be adapted to areas in which schools do not have work environments as stipulated in WS/M.

\section{Indigenous knowledge}

Indigenous knowledge is made up of the two words indigenous and knowledge. Indigenous is a word with a spectrum of meanings. Semali \& Kincheloe (1999) agree as they suggest that the word indigenous is ambiguous. Some meanings loaded in indigenous are traditional, local, natural and primitive. Whereas knowledge refers to power, a commodity or a tool particular local people are armed with. This study understands indigenous as local, traditional and natural when it discusses knowledge which it considered as a tool, commodity and power.

Other authors (Kibirige \& Van Rooyen, 2006) consider IK as: 'a legacy of knowledge and skills unique to a particular indigenous culture and involving wisdom that has been developed and passed on over generations' (p. 2). In interacting with the environment, for example, community members use Mathematics and Science adapted to fit their immediate context in order to understand the phenomena around them and, consequently, to improve their living standards. That is, the knowledge they have and apply is indigenous science and ethnomathematics as practiced at community level. This type of knowledge is what (Aikenhead \& Ogawa, 2007) refer to as a community's 'indigenous ways of living in nature' (p. 556).

However, IK is often neglected, or subsumed by the hegemonic nature of Western science/mathematics (WS/M) (Ogunniyi, 1998). The result is that the teaching and learning of science and mathematics adopts a monocultural perspective. This has surely contributed to the under recognition of cultural practices that involve Science and Mathematics as suitable for use as alternatives to formal work environments in CTL. 
Even though IK is shunned in some contexts, however, WS/M extracted and still extracts and appropriates some ideas from IK from all the areas of the world. IK is taken as a property; this makes it have value. Instead, IK as property and commodity locals in a given area possess can be showcased in an IK cafe. Doing so will not only serve tourist but also teachers who are posted to teach in areas they are not indigenous inhabitants. This also helps the teachers to see how they can possibly translate IK practices into the classroom (Ogunniyi, 2004).

As noted above that IK suffers under-recognition, so the chances are that some of the IK has not changed as new ideas in science surfaced. Also, chances are, if it has changed with the wave that made WS/M shift where it is now, IK might have been contaminated. IK as a component of a culture of a given community undergoes a state of change that can be for the better or adverse (Kincheloe \& Steinberg, 2008). So, when fusing IK with WS/M, as we aim to introduce as an alternative to formal work environment in CTL, it is important to neither essentialise nor uncritically embrace IK, nor to present it monolithically since cultural translation cannot be achieved.

\section{Cultural translation}

(Bassnett \& Lefevere, 1990) argue that cultural translation is the process of analysis of translation in its cultural context. That is some activities depicting the culture must be included in order for the material to be contextualised. (Bhabha, 1994), who came up with the idea, considers cultural translation as a process of removing activities which do not depict the culture of an area and replace them with those which are cultural related and found in that area. That is in the case of educational theories, ideas, designs and others from other areas they must be implemented using a cultural lens of the area they are being implemented. Cultural translation is a performative theory of daily life for not only the sub-Saharan African countries with schools situated in areas without work environments. The entire global community in similar situation can practice it. An analysis of the word translation using its origin and history means to carry the sense to another setting. Cultural roots in Science and Mathematics of different nations are often described using cultural activities of areas where the idea or theory came from. In most cases, Science and Mathematics curricula for sub-Saharan African countries is written using the lens or vision of "outsider's own" specific story. Illustrations of phenomena studied are those from outside the learners' culture. Such ideas are imported or exported without taking note that each culture has its explanation of such phenomena.

Instead the exporters or importers of educational ideas such as CTL or the notion that sub-Saharan African countries are culturally homogeneous attempt to adapt the way in which a Science educational idea is communicated to new audiences in order to respect their conception of the world and communicative habits and practices (Thompson, 2013). Translation in a sub-Saharan context must reflect sub-Saharan African context. What happens with the scientific concepts when they are de-territorialized within culturally diverse communities? How do relationships between culture of area of conception and export affect the recipients who use these science concepts? What is the effect of these changes on, say, gender formations? How do these new hybrid forms of cultural interaction 'translate' and domesticate particular political and ideological practices? For example, does the approach of learner-centredness or CTL in science mean the same thing in a school in a developed nation/area as in a rural sub-Saharan African school?

Given the very real cultural, political and ideological diversity in sub-Saharan African developing countries, it is imperative to seek a greater degree of differentiation in relation to scale, type and objectives. In order to adapt successfully to new educational contexts across national boundaries, cultural translation needs to be done. Cultural translating CTL in this study allows infusing IK instructional designs engaging CTLPP. That is answering research question (a). Since the discussion is on IK which is a component of culture I selected cultural historical activity theory which deals with culture and its historical aspects.

\section{THEORETICAL FRAMEWORK}

\section{Cultural historical activity theory (CHAT)}

Cultural historical activity theory (CHAT), with its roots in Karl Max's class theory, was used as an analytical tool since it looks for contradictions emerging in the systems to analyse in this study (Cole \& Engeström, 1993). Tensions or contradictions arise when the conditions within an activity put the subject in contradictory situations that can prevent achieving the object or the nature of the subject's participation in 50 the activity while trying to achieve the object. The activity systems under analysis reveals how they are linked to their context which is the focus of this study (Engeström, 1999). 
It rests on the premise that the culture and history of all hitherto existing communities search knowledge carefully to sustain the community. The resultant knowledge is used to uplift the community's living standards. According to this perspective, ever since human society emerged from its primitive and relatively undifferentiated state it has remained fundamentally to assign community members to different tasks to construct knowledge (the object) from observing natural phenomena around them and adapt them to their community, as seen in pottery, oil processing and crossing the river discussed above. All this is in pursuit of an ethnic community's interests and the subjects (the trainee teachers and community members) are guided by the community's rules. My further argument is there are two communities under analysis. There is a community of the trainee teachers and that of the community using IK where the trainee teachers come from. I point out that trainee teachers are familiar with what is happening in the community using IK since they were initiated during informal schooling to be responsible community members. The trainee teachers are aware of the rules found in the two activity systems and the activities since they are assigned some duties during division of labour. However, the trainee teachers' activity system is only familiar to them. A community member using IK is only familiar with his object which needs to be similar to the object of the trainee teachers. The given background suffices to allow us to come with a hybrid of Engeström's (2001) activity theory in Figure I. It shows the possibility of coexistence of WS/M and IK.

\section{Research paradigm}

An interpretivist paradigm underpinned this study (Janesick, 1998; Leedy \& Ormrod, 2010). In the interpretive paradigm there is no one conclusion and deductions are made based on the data obtained to formulate meaning. The interpretive research paradigm is subjective, studying people in their natural settings and having multiple interpretations (Cohen, Manion \& Morrison, 2010; Janesick, 1998). This model also seeks accurate summaries of intelligible detailed context from which the meaning of social actions become clear (King, Keohane \& Verba, 1994; Creswell, 2003). People perceive the subjective reality. (Morgan, 1980) reinforces this conception, saying, 'social reality is created and sustained through the subjective experience of people involved in any given practice' (p. 611). A case study approach was used with the cultural museum group who presented live presentations to the trainee teachers who observed, participated and were interviewed later.

\section{Research site and participants}

The participants engaged in order to answer the above stated research questions were 12 trainee Science and Mathematics teachers who were pursuing the Bachelor of Education Degree (BED) program at the research site, University of Namibia, Katima Mulilo Campus. Purposeful sampling was used to consider trainee teachers as research participants. The researcher taught them a module in which the component of IK was discussed and a need to relate to CTL arose. This premised the need to visit the cultural group. The site of the cultural group, with 13 members, was also used as a research site. These members included three adult males, two small boys and eight adult females.

\section{Data generating techniques}

To respond to research questions (a) and (b), the study used observation, audio-visual techniques and lesson plans and interviews. Trainees were tasked to observe, participate and search for Mathematics and Science practices akin to what is done in a formal work environment where WS/M is used from the presentations. After observing trainees were interviewed. The use of a number of instruments triangulated the data obtained.

Thereafter, a lesson plan assignment was given to trainees to see their responses. In the responses we expected to find whether there are IK practices they included as alternatives to formal work environments.

\section{Data presentation}

From the instruments used-observation of presentations, trainees' lesson plans, interviews and audiovisual techniques - the following data was obtained. Table 1 presents data that emerged from observations and found suitable to be used in CTL. Only those that were found to be important were recorded.

To triangulate the data, trainee teachers were tasked to work in groups of six and came up with lesson plans. One lesson plan in Mathematics and the other in Science came from each group. The outcomes of the two lesson plans are tabulated in Table 2. 
Table 1. Data generated from observation, audiovisual techniques and responses from trainee teachers

\begin{tabular}{|c|c|c|}
\hline \multicolumn{2}{|c|}{ Nature of Activity Explanation from the cultural group } & Views from reflections of trainee teachers \\
\hline $\begin{array}{l}\text { Processing of clay } \\
\text { to use in pottery }\end{array}$ & $\begin{array}{l}\text { Clay is burnt to remove organic matter not yet } \\
\text { changed into soil, crushed to come up with smaller } \\
\text { particles, molded, and the products cured using } \\
\text { heat to make them durable. }\end{array}$ & $\begin{array}{l}\text { Clay is a material that comes under the section of materials around } \\
\text { us. Science in the textbook discusses it and points that curing using } \\
\text { heat is done to harden clay. It can be a starting point and good for } \\
\text { learners to understand other processes like alloying. }\end{array}$ \\
\hline Processing of hide & $\begin{array}{l}\text { Fat removed using sharp objects, ashes added } \\
\text { before wringing the hide to soften it. }\end{array}$ & $\begin{array}{l}\text { School science discusses tanning. Ashes used act as a base since they } \\
\text { corrode the fur on the hide and leaves it clear of it. }\end{array}$ \\
\hline $\begin{array}{l}\text { Processing of } \\
\text { mungongo seeds to } \\
\text { make cooking oil }\end{array}$ & $\begin{array}{l}\text { Removed nut is crushed and added to water. } \\
\text { Lighter impurities settle on the surface followed by } \\
\text { oil and water at the bottom. }\end{array}$ & $\begin{array}{l}\text { Terms like lighter than, heavier than which come with oil processing } \\
\text { can be used in maths. They can assist learners to contextualize the } \\
\text { mentioned concepts and empower them in activities like ordering } \\
\text { and comparing numbers in numeracy. }\end{array}$ \\
\hline Setting of traps & $\begin{array}{l}\text { Pulleys are made use of while friction is taken } \\
\text { cognizant of by making surfaces in contact smooth. }\end{array}$ & $\begin{array}{l}\text { Factors that reduce friction are exploited for the benefit of trapping } \\
\text { animals. Ropes used are passed through pulley system to reduce } \\
\text { friction. }\end{array}$ \\
\hline $\begin{array}{l}\text { Cultural } \\
\text { artifacts/games }\end{array}$ & $\begin{array}{l}\text { Earthen ware pots, baskets, drums, bow and arrows } \\
\text { all come in different geometrical shapes. Games } \\
\text { facilitate counting. }\end{array}$ & $\begin{array}{l}\text { Diagrams drawn on the cultural artifacts follow a certain pattern. } \\
\text { Artifacts are of geometric shapes. } \\
\text { Numeracy development as they count playing games. }\end{array}$ \\
\hline
\end{tabular}

Table 2. Data generated from lesson plans after observation

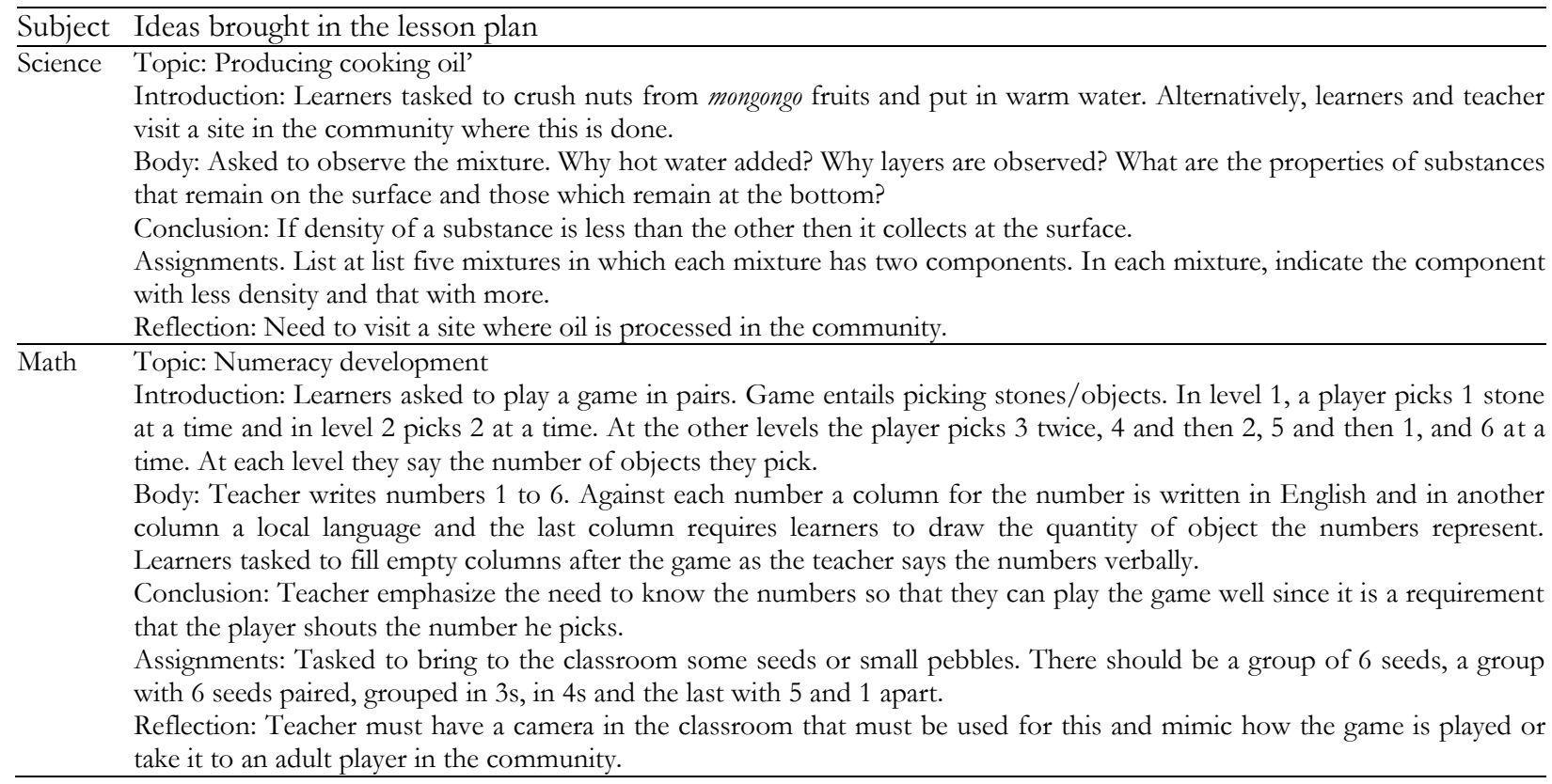

Data from Table 2 was a result of collating what was observed. This was not only done for lesson planning but also data that emerged from interviews.

\section{Data generated from interviews}

Data in Table 3 was obtained by selecting ideas given by students. The ideas were analysed to see the central idea they conveyed. This then resulted in coming up with ideas which were common from each of the 12 trainee teachers and then analysed.

\section{Analysis of data generated from explanations}

From Table 1, it is evident that the activity system of each of the two activities presented has the same object. This will bring the same theme for each idea pointed out. In the case of clay processing the third generation activity system presented in Figure 1 above will have in its potential shared area the idea of a durable material made out of clay. In both the two activity systems, activities organised to prepare clay are all aimed at producing a material which can be used by the community and made durable through heating. Trainees also perceived that there are some areas where IK and WS are similar and this is evident when they 
Table 3. Data generated from interviews

\begin{tabular}{|c|c|}
\hline Interview questions & Main idea from the responses \\
\hline $\begin{array}{l}\text { 1. Do you sometimes allow learners to } \\
\text { interact with community members } \\
\text { applying concepts you teach? }\end{array}$ & $\begin{array}{l}\text { We do not have community members who are applying concepts we teach in work place } \\
\text { environments. Sometimes we realize this when the school plans a trip to visit bigger } \\
\text { towns where industries are then learners will have an opportunity to interact with them } \\
\text { and acquire science and maths language. }\end{array}$ \\
\hline $\begin{array}{l}\text { 2. From what you have observed from } \\
\text { the presentation, what are your } \\
\text { experiences in infusing IK ideas as we } \\
\text { aim to bring tenets of CTL in classrooms? }\end{array}$ & $\begin{array}{l}\text { One needs to identify practices in the community which have science ideas and then a } \\
\text { knowledgeable community member selected who comes and discuss the idea with } \\
\text { learners to enable them reflect what they are taught. Alternatively the teach reveals } \\
\text { application of concept taught. }\end{array}$ \\
\hline $\begin{array}{l}\text { 3. Do you perceive some examples from } \\
\text { the presentation which allows you } \\
\text { to engage CTL in a classroom? }\end{array}$ & $\begin{array}{l}\text { An example can be that of a trap for an animal where community members have good } \\
\text { understanding that the points of contact need to be very smooth to reduce friction. } \\
\text { Other examples are; the filtering of crude oil made from seeds to obtain the purer form } \\
\text { and the understanding of proportion as they try to determine the rate of movement of } \\
\text { water which can flood a homestead near the banks of the river. }\end{array}$ \\
\hline $\begin{array}{l}\text { 4. As a teacher what challenges do } \\
\text { you think you might encounter as you } \\
\text { try to bring IK during situated cognition? }\end{array}$ & $\begin{array}{l}\text { One needs to have sufficient science and mathematics content knowledge to avoid use of } \\
\text { practices which are myths. Such a challenge can be avoided if one belongs to that } \\
\text { community since he or she would have been apprenticed to IK practices from an early } \\
\text { stage in a way that there is chances for him or her to detect myths in IK. }\end{array}$ \\
\hline $\begin{array}{l}\text { 5. Do you agree or disagree that you } \\
\text { were initiated into the knowledge which } \\
\text { the cultural group presented }\end{array}$ & $\begin{array}{l}\text { We are part of that cultural group in terms of knowing what they are presenting but we } \\
\text { are not active members in participating at this moment. However, at home we engage in } \\
\text { all what they have presented and we are still currently learning. }\end{array}$ \\
\hline
\end{tabular}

Trainee teachers' activity system interacting with cultural group's activity system

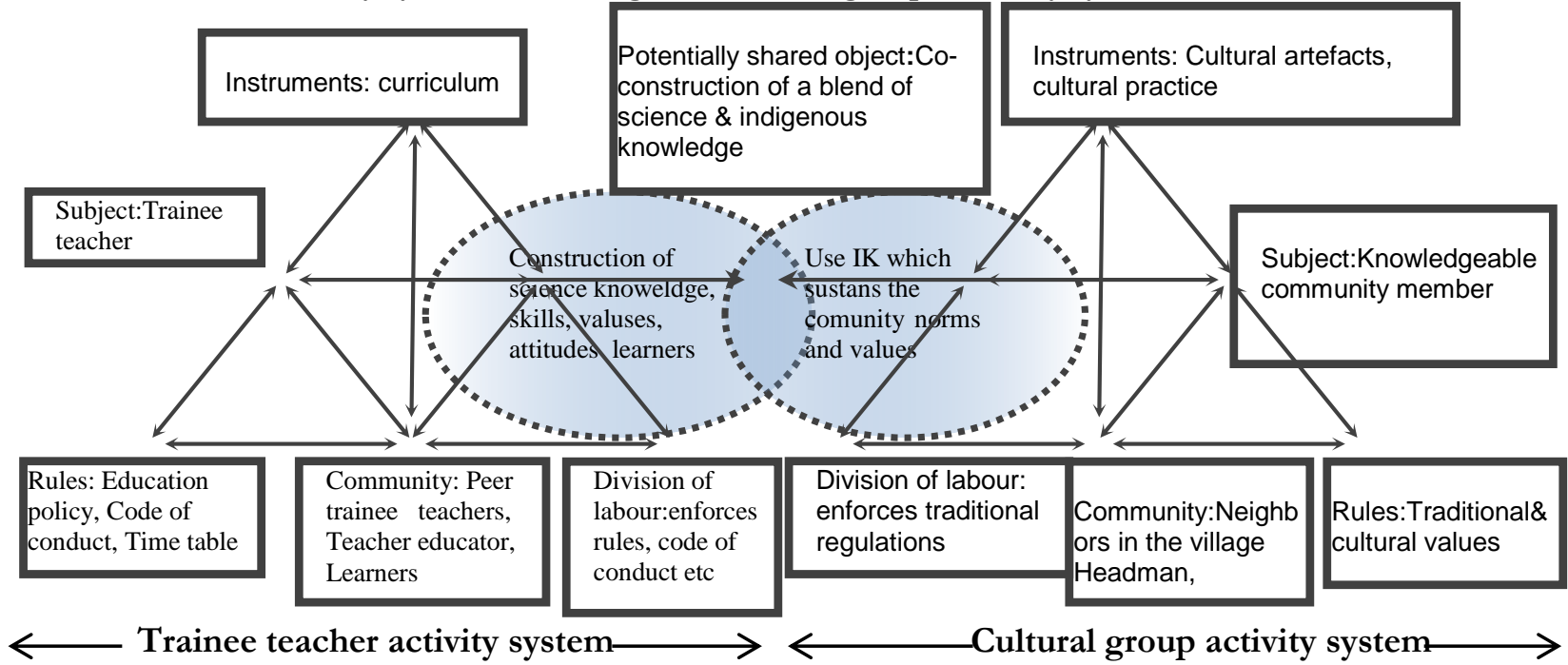

Figure 1. Two activity system in interaction (Adapted from Engeström, 2001)

observed that the points in contact in a trap need to be very smooth to reduce friction. This idea is also seen in WS as it suggests that friction is reduced by making points or areas in contact smooth.

In hide processing, the two activity systems' main activity is removing fur from the hide. Ash is used by indigenous communities and WS uses a convectional alkaline substance. In all they end up having hide free from fur.

A similar case is observed in row 3, 4 and 5 of Table 1 above. Mungongo seed processing, setting traps and geometrical shapes on cultural artefacts have some ideas which can facilitate the use of CTL as learners end up knowing where the concept is applied. In observing these practices trainees who were not aware of such a similarity pointed out that "what is taught in WS can be contextualized using IK practices" This manifestation answers research question (a) since trainees did not have experience of and were not aware of how WS concepts analysed were applied in IK practices.

\section{Analysis of data from lesson plan}

Data from Table 2 suggests that trainees noticed that CTL can be engaged by trainees through infusion of IK practices as the science lesson plan shows that learner will at some time visit the community where such an activity is conducted, learners interact with knowledgeable community members. Paying a visit to an IK 
practice site allows a learner to see where WS concepts are applied in his community. In doing so CTL takes place.

In the lesson plan for mathematics, the activity suggested by the trainee teachers allows the learners to participate in a cultural game. As they do so learners develop their numeracy skills in an authentic situation. The trainees' recognition of number sense in cultural games comes as an indication of how CTL instructional design, using IK practices can be implemented in schools.

In both lesson plan trainees perceived that IK practices can be used to contextualize teaching and learning of Mathematics. The presence of areas where the trainees refer to IK is evidence enough for this. Their perceptions are further revealed in the interviews we analyse below.

\section{Analysis of data from interviews}

From the interviews the revelations are trainees serve an apprenticeship program as they interact with adult members in their community. Figure 1 reveals this as it shows that trainees appear as components of the community in the activity system of the community. Their experiences as science teachers is a teacher encounter challenges when the teacher does not have sufficient Science or Mathematics content knowledge to detect Science and Mathematics practiced in the community. From the view of the trainee teachers they indicate that there are examples in the community which can be used in CTL design by teachers. Examples given of friction were just part of what was observed by the trainee teachers. Finally, trainee teachers' view were for them to engage CTL design in classrooms they need to take learners for a trip where they can interact with community members working in environments where they are applying concepts or theories taught in Mathematics or Science. On how CTL instructional design using IK practices, can be implemented in schools, trainees pointed out that one need to have sufficient knowledge content which he then uses to detect practices which reflects science. The practices can then be related to what WS explains. For example, trainees indicated that teachers must show that community members use materials which are smooth in traps and the same understanding is used to reduce friction in moving bodies in contact when explaining factors which determines friction. The analysis of data done in the previous sections allows us to discuss the findings which follow.

\section{FINDINGS}

Observations done answered research question (a). These observations and interviews conducted revealed that trainee teachers were not able to engage with CTL before the encounter with presentations from the cultural group. They acknowledged that they are aware of the practices since they are initiated with such activities and interact with the knowledgeable community members who share with them that knowledge during informal schooling (see Figure 1 which consolidates this conception). The third generation activity system agrees to this as we see the trainee teachers appearing twice. In the trainee teachers' activity system they come as subjects and in the community member activity system they are part of that community. Belonging to both sections in the two activity systems is a reflection that they are aware of the social and historical development of practices in their communities. However, contradictions arise since trainees do not bring these everyday experiences into classroom for learners to experience authentic situations of Science and Mathematics concepts taught.

Evident to this is previous experiences of trainee teachers were not supportive of designing CTL environments in rural schools in the Zambezi Region. This was based on their understanding that for CTL to be engaged there is a need to have formal work environments where learners can interact with those applying theories in Science and Mathematics which teachers teach to learners (see Brown, Collins, \& Duguid, 1989). However, data generated from observation and audio-visual techniques at the cultural museum lead trainees to see that cultural practices, artefacts and explanations presented were part of the socio-cultural activities in agreement with what they understood of the phenomena using WS/M lens (See Table 1, column 2 and 3). This led them to finally change their behaviour and view that CTL environments can be designed for learners in rural schools in the regions that lack formal work environments which allow learners to interact with community of practice. This can be achieved through bringing the cultural artefacts in the classroom and use them as models and also to develop the necessary Science and Mathematics language required by the learners. Cultural artefacts contextualize Science and Mathematics concepts taught as they are part of the learners' prior knowledge. Such a consideration enhances a multicultural focus to science teaching thereby addressing equity and access to knowledge which the teacher want the learner to construct (Campbell, Lubben \& 
Dlamini, 2000). This is revealed in their two lesson plans where they indicated that teachers need to mimic cultural practices in their classroom discourses (see Table 2).

To understand how CTL can be implemented in under resourced schools or those without formal work environments near them, it was suggested that learners could be taken to the community. Alternatively, a member from the community well versed in the concept discussed can be invited to the school to have a classroom talk. His role will be to explain to the learners the reason behind each stage in the concept for example clay. Learners will then reflect on this and the teacher on the other hand can indicate where the concept taught is applied in the community. This revelation is in agreement with what we are observing in the CHAT figure above where the object from the two activity systems are placed at the centre implying that they have the same theme or play the same role.

Furthermore, in both cases collaboration of knowledge with the learners to scaffold them into the culture of practice is achieved (see Lave \& Wenger, 1991). This response comes from what was heard from trainee teachers on analysis of data from audio-visual techniques and interviews. Trainee teachers further suggested that as pottery is a process done in most communities, it could provide a dependable learning context. Some of the processes involved in pottery aim to come up with a durable material. Further suggestion from trainee teachers was alloying is analogous to heat curing of clay products. Patterns in pottery artefacts were found to be good at initiating learners in pattern identification in maths.

The benefits were that use of IK in CTL culturally translates the learning of Science and Mathematics concepts. CTL is premised on the conception that there should be areas where learners should interact and relate subject matter content to real world situations with those in the community of practice. The schools in which these trainees do their teaching practices do not have formal work environments. An alternative would be to consider using how Science and mathematics are viewed in the community. In conventional work environments, processing of materials is based on the use of WS/M, which is a tool humans use and perfect every time they engage with it (Engeström, 2001). Similarly, IK is also a tool perfected each time the users apply it. This has led it to be part of their socio-cultural activities where knowledge is manifested. The complementing effect of the two knowledge systems makes it possible to have certain areas where they are in harmony (see cultural historical theory explained above).

Another benefit is that a cultural and historical approach in teaching Science and Mathematics is brought into the classroom. The teacher will discuss different views of learners from different ethnic groups. The teacher can search for concepts related to science in each ethnic group represented in the classroom.

Finally, both learners and teachers are equipped with indigenous pedagogical content knowledge and indigenous pedagogical technical content knowledge. The explanations from the knowledgeable community member equip learners with science and mathematics language. The language acquired will be used by the teacher and learners to talk Science or Mathematics. Artefacts brought by the knowledgeable community member allow both teacher and learners to familiarises themselves with the technical aspects of the artefact which is part of the technical content knowledge. These are concepts obtained when Shulman's, 1987 PCK is viewed using an indigenous knowledge lens. Learners and teachers bring from the site which present CTL some prior knowledge related to how the phenomena operate and also have some skills to handle.

\section{RECOMMENDATIONS}

The study considered the possibility of using pottery activities as done at community level to illustrate Science and Mathematics theory in practice. This is, of course, not the only IK practice that can be employed as an alternative in CTL. The other cultural practices reflecting Science or Mathematics can still be investigated. These can also be used as an alternative in CTL. Such areas are possible areas of future research.

On account of the fact that the trainee teachers who participated agreed that it is possible to consider cultural practices, cultural games, and cultural artefacts as an alternative to work environments, it is necessary to sensitize these findings to others.

\section{CONCLUSION}

The two knowledge systems, IK and WS/M, are abstract. We cannot quantify them and cannot see them. However, they are both manifested in our socio-cultural practices. Yet, we only consider the cultural manifestation of one culture when intending to implement CTL. That is the Eurocentric culture that is in our curricula materials as guidelines on what to teach, but not how. 
The hegemonic nature of WS/M short-changes our learners as we adopt a monocultural approach despite the fact that our communities are not culturally homogeneous. This research indicates that cultural translation can enable Science and Mathematics learning using CTL even in the absence of formal work environments.

\section{REFERENCES}

Aikenhead, G.S. and Ogawa, M., 2007. Indigenous knowledge and science revisited. Cultural Studies of Science Education, 2(3), pp.539-620.

Bassnett, S. and Lefevere, A., 1998. Constructing cultures: Essays on literary translation (Vol. 11). Multilingual Matters.

Berns, R.G. and Erickson, P.M., 2001. Contextual Teaching and Learning: Preparing Students for the New Economy. The Highlight Zone: Research@Work, 5, pp. 2-9.

Bhabha, H.K., 2012. The location of culture. New York: Routledge.

Bond, L.P., 2004. Using Contextual Instruction to Make Abstract Learning Concrete. Techniques: Connecting education and careers, 79(1), pp.30-33.

Brown, J.S., Collins, A. and Duguid, P., 1989. Situated cognition and the culture of learning. Educational researcher, 18(1), pp.32-42.

Campbell, B. and Lubben, F., 2000. Learning science through contexts: helping pupils make sense of everyday situations. International Journal of Science Education, 22(3), pp.239-252.

Cohen, L., Manion, L. and Morrison, K., 2013. Research methods in education. (6 ${ }^{\text {th }}$ Edn.). London: Routledge.

Cole, M. and Engeström, Y., 1993. A cultural-historical approach to distributed cognition. Distributed cognitions: Psychological and educational considerations, pp.1-46.

Creswell, J.W., 2013. Research design: Qualitative, quantitative, and mixed methods approaches. Sage publications.

Engeström, Y., 1999. Activity theory and individual and social transformation. I Y. Engeström, R. Miettinen \& RL. Punamäki (red): Perspectivies on activity theory.

Engeström, Y., 2001. Expansive learning at work: Toward an activity theoretical reconceptualization. Journal of education and work, 14(1), pp.133-156.

Freire, P., 1993. A critical encounter. USA and Canada: Routledge.

Salomon, G., 1997. Distributed cognitions: Psychological and educational considerations. Cambridge University Press.

Gerdes, P., 2001. Exploring the game of" julirde": A mathetmatical-educational game played by fulbe children in Cameroon. Teaching Children Mathematics, 7(6), pp.321-327.

Janesick, V.J., 1998. " Stretching" exercises for qualitative researchers. Thousand Oaks, CA: Sage.

Kibirige, I. and Van Rooyen, H., 2006. Enriching science teaching through the inclusion of indigenous knowledge: IK in the science classroom. Teaching science in the OBE classroom, pp.235-247.

Kincheloe, J.L. and Steinberg, S.R., 2008. Indigenous knowledges in education: Complexities, dangers, and profound benefits. Handbook of critical and indigenous methodologies, pp.135-156.

King, G., Keohane, R.O. and Verba, S., 1994. Designing social inquiry: Scientific inference in qualitative research. Princeton university press.

Lave, J. and Wenger, E., 1991. Situated learning: Legitimate peripheral participation. Cambridge university press.

Leedy, P.D. and Ormrod, J.E., 2010. Practical research: Planning and design. (9th Edn.) New Jersey: Pearson Education.

Mazzeo, C., 2008. Supporting student success at California community colleges. Prepared for the Bay Area Workforce Funding Collaborative Career by the Career Ladders Project for California Community Colleges.

Mezirow, J., 2000. Learning as Transformation: Critical Perspectives on a Theory in Progress. The Jossey-Bass Higher and Adult Education Series. Jossey-Bass Publishers, 350 Sansome Way, San Francisco, CA 94104.

Morgan, G., 1980. Paradigms, metaphors, and puzzle solving in organization theory. Administrative science quarterly, pp.605-622.

Namibia. Ministry of Basic Education and Culture, 2010. The National Curriculum for Basic Education. NIED, Okahandja.

Ogunniyi, M.B., 1988. Adapting western science to traditional African culture. International journal of science education, 10(1), pp.1-9.

Ogunniyi, M.B., 2004. The challenge of preparing and equipping science teachers in higher education to integrate scientific and indigenous knowledge systems for their learners. South African Journal of Higher Education, 18(3), pp.289-304.

Semali, L.M. and Kincheloe, J.L., 1999. Introduction: What is indigenous knowledge and why should we study it. What is indigenous knowledge, pp.157-178.

Shulman, L., 1987. Knowledge and teaching: Foundations of the new reform. Harvard educational review, 57(1), pp.1-23.

Thompson, P., 2013. Learner-centred education and 'cultural translation'.International Journal of Educational Development, 33(1), pp.48-58.

Whitehead, A.N., 1929. The aims of education and other essays. New York: Macmillan. 